\title{
PRELIMINARY DESIGN METHOD FOR ROCKING AND NEGATIVE STIFFNESS SYSTEMS
}

\author{
Natalia Reggiani Manzo ${ }^{1}$, and Michalis F. Vassiliou ${ }^{1}$ \\ ${ }^{1}$ ETH Zürich \\ Institute of Structural Engineering \\ Stefano-Franscini-Platz 5, 8093 Zürich, Switzerland \\ \{reggianimanzo,vassiliou\}@ibk.baug.ethz.ch
}

\begin{abstract}
This paper proposes a simple analytical system that can be used to describe the dynamics of Negative Stiffness Bilinear Elastic (NSBE) systems, and consequently design them in a simpler manner. The NSBE oscillator is a mathematical idealization, which can be used to describe rocking structures with or without flexible restraining systems or curved extension at their bases. The paper defines the characteristic quantities to make the bilinear system and actual rocking structures equivalent.

A simpler "equivalent" system to describe the behavior of NSBE systems is proposed: The equivalent system is the Zero Stiffness Bilinear Elastic (ZSBE) system, which is a bilinear system with zero stiffness in the second branch. The ZSBE system is useful and simpler because it needs one parameter less than the NSBE to be defined. The paper proceeds by defining the "Equal Displacement" and "Equal Energy" rules that provide estimates of the maximum displacement of the NSBE based on the response of the ZSBE. Using a simpler system to predict the response of a more complicated one, is a concept similar to the R $\mu T$ relations that provide estimates of the response of bilinear yielding systems based on the response of an equivalent linear elastic system. However, the method should not be confused with the approach of FEMA 356: it does not resort to a linear elastic system but to the ZSBE.

Finally, the preliminary design of a real rocking structure is presented, as a case of study. The paper compares the response predicted by the proposed methodology to the one predicted by a more accurate numerical analysis.
\end{abstract}

Keywords: negative stiffness systems, dimensional analysis, non-linear dynamics, bilinear systems 


\section{INTRODUCTION}

Rocking has been proposed as a seismic isolation method for both bridges [1-20] and buildings [21-23], because uplift works as a mechanical fuse and limits the design forces of both the superstructure and the foundation. Unlike structures designed to yield, the free rocking rigid block exhibits negative post-uplift stiffness [24]. In particular, this paper focuses on negative stiffness systems that are designed to sustain rocking motion without sliding [2532], and do not exhibit hysteretic damping. Thus, it loads and unloads on the same branch. These systems do not accumulate displacements as negative stiffness hysteretic systems would. To avoid confusion, note that this paper uses the term "elastic" to describe not only linear elastic systems but all systems that unload on the same branch, linear or nonlinear. Therefore, an unrestrained rocking system is a negative stiffness elastic system.

Plastic design has found its way to practice, partially because a simplified design methodology that is based on the linear elastic response spectrum has been developed. For most structures designed to yield, a time history analysis is not required and an approach based on linear elastic spectra is allowed. This convenient design approach was originally developed for elastoplastic systems, including the ones exhibiting post-yield hardening. It has been extended to include recentering (rocking) systems exhibiting positive post-uplift stiffness [33, 34]. However, it is not applicable to negative stiffness rocking systems, because there is no "equivalent linear elastic system" for them [35]. Therefore, time-consuming time history analysis is required and the linear elastic response spectra that are defined by codes become useless for such structures.

This paper suggests that there can be a simplified design method for Negative Stiffness Bilinear Elastic (NSBE) systems (Fig.1a), based not on an equivalent linear elastic system, but on an equivalent bilinear elastic system of constant restoring force (i.e., zero post-uplift stiffness) - a Zero Stiffness Bilinear Elastic (ZSBE) system (Fig.1b). Even though the equivalent ZSBE system does not present the convenience of a linear elastic system where the response scales proportionally to the excitation, it is useful because it reduces the dimensionality of the problem and it allows the development of design spectra (not linear elastic) for negative stiffness systems.

(a)

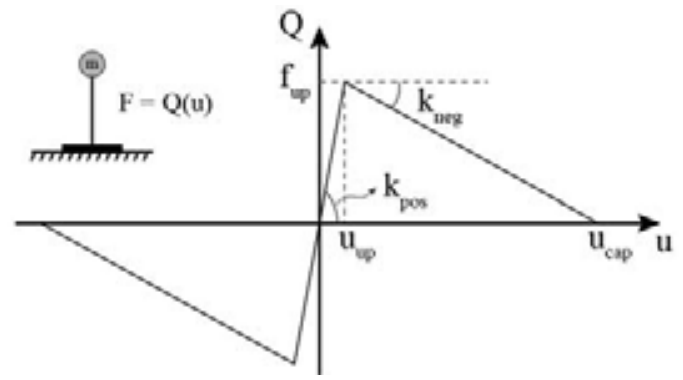

(b)

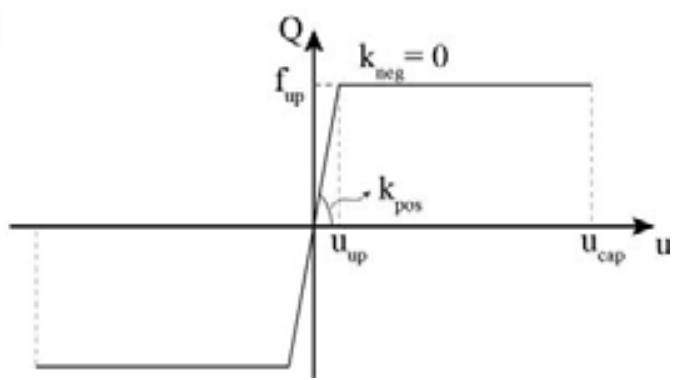

Figure 1: a) Characteristic pushover curve of the Negative Stiffness Bilinear Elastic (NSBE) system; b) Proposed bilinear elastic system of constant restoring force (Zero Stiffness Bilinear Elastic [ZSBE]) system.

It should be noted that the results of this study are not directly applicable to design procedures. However, they suggest approaches that might be used to develop a rational design procedure for earthquake resistance of rocking structures. 


\section{EQUIVALENT DESCRIPTION OF ROCKING SYSTEMS WITH NSBE SYSTEMS}

One of the challenges in designing a rocking structure is that for a given height of a flatbased unrestrained rocking structure, usually defined by architectural considerations, its displacement capacity (i.e., the displacement that would cause overturn) is coupled to its uplifting force, because they both depend on its slenderness $\alpha$ (or, equivalently, on its base width $2 b$ ). Therefore, extending the base to increase the displacement capacity of the structure causes an increase in the design forces of both the superstructure and the foundation.

In an effort to isolate buildings via a rocking story, Soviet engineers [36] were the first to suggest a way to decouple the displacement capacity from the uplift acceleration: They extended the base of the block by a curved part. This increases the displacement capacity while keeping the uplifting acceleration constant [8]. The post-uplift stiffness can be positive or negative depending on the curvature of the extension. A similar behavior can be obtained by using a flexible restraining system $[14,16]$.

The idealized systems presented above assume that the structure is rigid - a questionable assumption as the size of the blocks increase. Fig.1a shows the force-deformation curve of a rocking structure, when its deformability is considered [37-44]. In this case, the pre-uplift displacement is not zero but takes a finite value $u_{u p}$. Therefore, all systems cited above can be described by an elastic bilinear system, up to a linear approximation.

The SDOF NSBE studied here is shown in Fig.1a. It has a mass $m$ and a restoring force described by Fig.1a. The initial positive stiffness $\left(k_{p o s}\right)$ branch represents any pre-uplift deformability. The second branch has negative stiffness $\left(k_{n e g}\right)$, and it starts at the uplift displacement $\left(u_{u p}\right)$. The system displacement capacity $\left(u_{c a p}\right)$ is defined as the displacement that results to zero restoring force, even though there are rare cases where a system can dynamically exceed this displacement without collapsing.

Based on its characteristic pushover curve, the oscillator's equation of motion is:

$$
\begin{gathered}
m \cdot \ddot{u}(t)+f_{u p} \cdot \frac{u(t)}{u_{u p}}=-m \cdot \ddot{u}_{g}(t), \quad|u(t)| \leq u_{u p} \\
m \cdot \ddot{u}(t)+f_{u p} \cdot\left(\frac{u_{c a p}-u(t)}{u_{c a p}-u_{u p}}\right)=-m \cdot \ddot{u}_{g}(t), \quad|u(t)|>u_{u p}
\end{gathered}
$$

The upper sign in Eq. 2 corresponds to a positive displacement and the lower to a negative displacement.

The main source of energy dissipation in rocking structures with protected ends is impact damping - unless extra damping is provided. For this reason, this paper assumes that the proposed NSBE model dissipates energy instantaneously. When the displacement is equal to the uplift displacement (i.e., when there is impact in the case of rocking structures), the integration is halted, and the post impact velocity is computed by a coefficient of restitution:

$$
r_{c}=\frac{\dot{u}_{\text {postimpact }}}{\dot{u}_{\text {preimpact }}}
$$

Herein, the ratio of the preimpact to postimpact velocities will be assumed equal to 0.95 . Notably, the system unloads on the same branch and does not dissipate energy while unloading (apart from the instantaneous energy loss when it reaches the yielding displacement).

For the case of rigid systems, the parameters of the system of Fig. 1a that make it mathematically equivalent to a variety of rocking systems are given in Table 1 and named $\tilde{m}, \tilde{f}_{u p}$, 
and $\tilde{u}_{c a p}$. Note that in order for the system of Fig.1a to be equivalent to these rocking systems, the excitation used for the equivalent bilinear system needs to be multiplied by a factor $\Gamma$, also given in Table 1. Then, the equation for the equivalent bilinear system becomes:

$$
\tilde{m} \cdot \ddot{u}(t)+\tilde{f}_{u p} \cdot\left(1-\frac{u(t)}{\tilde{u}_{c a p}}\right)=-\Gamma \tilde{m} \cdot \ddot{u}_{g}(t)
$$

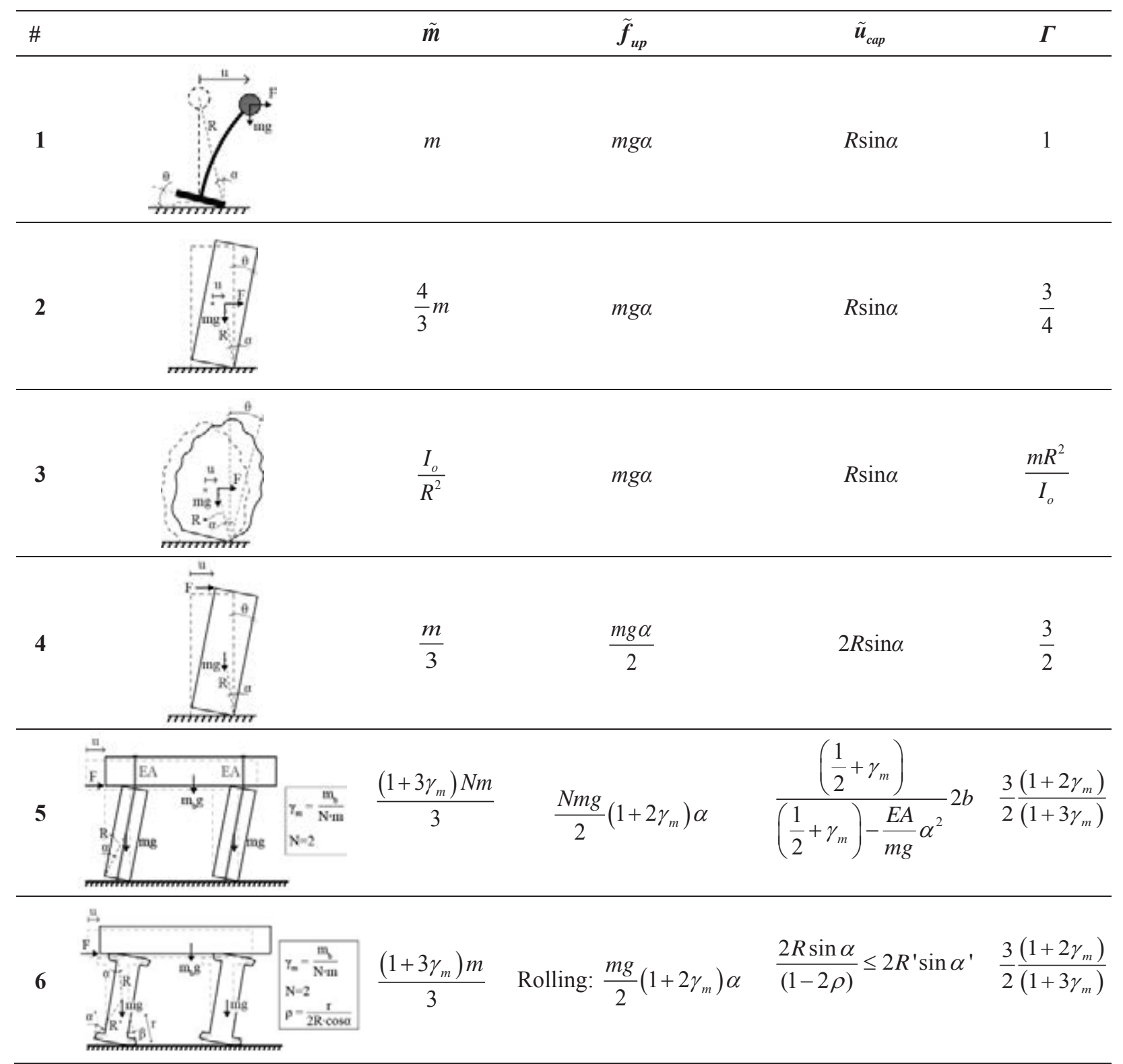

Table 1: Parameters of the bilinear elastic system for different rocking systems 


\section{EQUAL DISPLACEMENT AND EQUAL ENERGY RULE}

Using the elastic spectrum for the analysis of negative stiffness structures would have been very convenient as engineers are used to it and as elastic spectra for design already exist and are included in codes. However, this is not feasible for NSBE systems, because their response has been proven to be uncorrelated to any "equivalent" elastic system [35].

Therefore, this section defines Equal Displacement and Equal Energy rules that are applied not on an equivalent elastic system but on an equivalent ZSBE system (Fig.1b). We refer to it as "equivalent," but this does not imply that it is linear elastic. It is a bilinear elastic system with finite pre-uplift displacement and zero post-uplift stiffness system.

To correlate the responses of the NSBE and of the ZSBE, the quantity of interest is the ratio:

$$
\gamma=\frac{u_{d e m, N S}}{u_{d e m, Z S}}
$$

where $u_{d e m, N S}$ and $u_{d e m, Z S}$ are the maximum displacements of the NSBE and ZSBE systems, respectively.

The Equal Displacement rule assumes that the NSBE and the equivalent ZSBE system will experience the same maximum displacement (Fig.2a):

$$
u_{\text {dem }, N S}=u_{\text {dem }, Z S} \rightarrow \gamma_{E D}=1
$$

The Equal Energy rule assumes that the monotonic loading curves of the NSBE and the ZSBE system will produce the same work, that is, the two shaded areas in Fig.2b are equal. Based on Fig.2b, one can compute that the Equal Energy rule gives:

$$
\gamma_{E E}=\frac{u_{d e m, N S}}{u_{d e m, Z S}}=\frac{u_{c a p}}{u_{d e m, Z S}}-\sqrt{\frac{\left(u_{c a p}-u_{u p}\right)}{u_{d e m, Z S}} \cdot \frac{\left(u_{c a p}-2 \cdot u_{d e m, Z S}+u_{u p}\right)}{u_{d e m, Z S}}}
$$

(a)

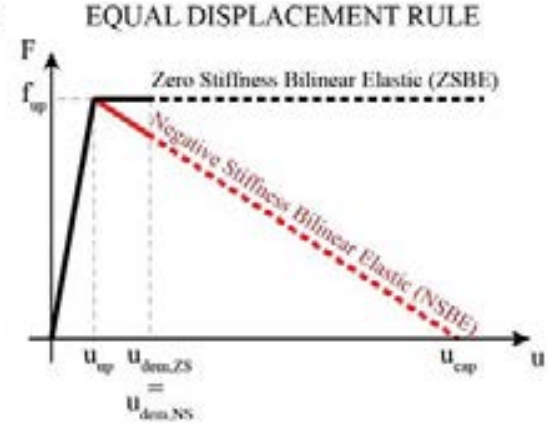

(b) EQUAL ENERGY RULE

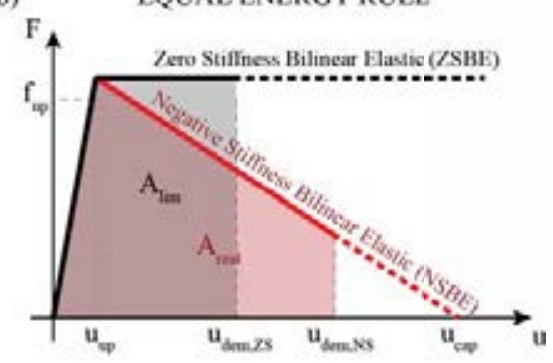

Figure 2: a) Equal Displacement, and b) Equal Energy rules for NSBE systems

\section{RESPONSE OF RIGID-NEGATIVE STIFNNES SYSTEMS TO RECORDED GROUND MOTIONS}

This section explores the accuracy of the rules defined in the section above, when applied to NSBE systems that present minimal pre-uplift displacement, i.e. systems with small $u_{u p}$. 


\subsection{FEMA P695 Ground Motions}

There is no consensus in the engineering community on what ground motions should be used in time history analysis. This paper focuses on the far-field set of ground motions proposed by FEMA P695 [45].

\subsection{Median displacement spectra}

Seismic design does not involve a single excitation, but a set of excitations that characterize the seismic hazard at a given site. Thus, this paper compares NSBE and ZSBE not by comparing their responses to individual ground motions, but by comparing the statistics of the responses to ensembles of ground motions [46]. The Equal Displacement and Equal Energy rules are assessed by focusing on the median displacement spectra for three variations of the set: scaled so that their PGV is equal to $0.5 \overline{\mathrm{PGV}}$, or $1.0 \overline{\mathrm{PGV}}$, or $2.0 \overline{\mathrm{PGV}}$. $\overline{\mathrm{PGV}}$ is defined as:

$$
\overline{\mathrm{PGV}}=\underset{i=1 \ldots N}{\operatorname{median}}\left(\sqrt{\mathrm{PGV}_{i_{x}} \cdot \mathrm{PGV}_{i_{y}}}\right)
$$

where $N$ is the number of ground motions and $x$ and $y$ are their two components.

\subsection{Equal Displacement Rule for NSBE systems}

Fig.3a plots the median of the maximum displacement of the NSBE stiffness system as a function of its strength normalized by the system's self-weight $\left(f_{u p} / \mathrm{mg}\right)$ for several values of the displacement capacity. The uplift displacement is set to $u_{u p}=5 \times 10^{-4} \mathrm{~m}$ to study quasi-rigid systems. For reasons of plot clarity, each line is plotted only for $f_{u p} / m g>\left(f_{u p} / m g\right)_{\text {crit }}$, where $\left(f_{\text {up }} / \mathrm{mg}\right)_{\text {crit }}$ is the maximum uplift strength for which there is failure. The figure shows that:

a) As long as the system is not close to failure, the displacement only loosely depends on the displacement capacity. So, when the system is not close to failure, instead of computing a different spectrum for each displacement capacity, one can compute the spectrum for the ZSBE system (i.e. for an NSBE with $u_{c a p} \rightarrow \infty$ ) and use it to calculate the displacement demand on any NSBE of the same strength.

b) As the system gets closer to collapse, the "Equal Displacement rule" does not apply and is unconservative: Systems with smaller displacement capacity exhibit larger displacements than the ones with larger displacement capacity. Moreover, close to failure the slope of the spectrum increases dramatically, i.e. a small decrease of the system strength would lead to a tremendous increase of the maximum displacement. This is not in agreement with a rational design, in which it would be required that this steep part is avoided.

\subsection{Equal Energy rule for NSBE systems}

Fig.3a show that the Equal Displacement rule is on the unconservative side, especially as the displacement demand approaches the capacity. To examine the performance of the Equal Energy rule, Fig.3b presents the median of the maximum displacement $u_{\max }$ divided by the factor $\gamma_{E E}$ (Eq.7) as a function of the system normalized strength $f_{u p} / m g$. The plots are constructed for several values of displacement capacity $u_{\text {cap }}$ and for uplift displacement $u_{\text {up }}=5 \times 10^{-4} \mathrm{~m}$.

The curves almost collapse to a unique curve, the one that represents the ZSBE system. Notably, this happens for all 3 different scalings of the ground motions. Hence, the Equal Energy rule gives a good estimate of the maximum displacement of NSBE systems with a finite displacement capacity. Comparing the Equal Displacement to the Equal Energy rule, the 
former is simpler, but the latter is overall more conservative, especially for larger displacements. Therefore, unless there is a reason to opt for simplicity, the use of the Equal Energy rule is proposed.

(a)
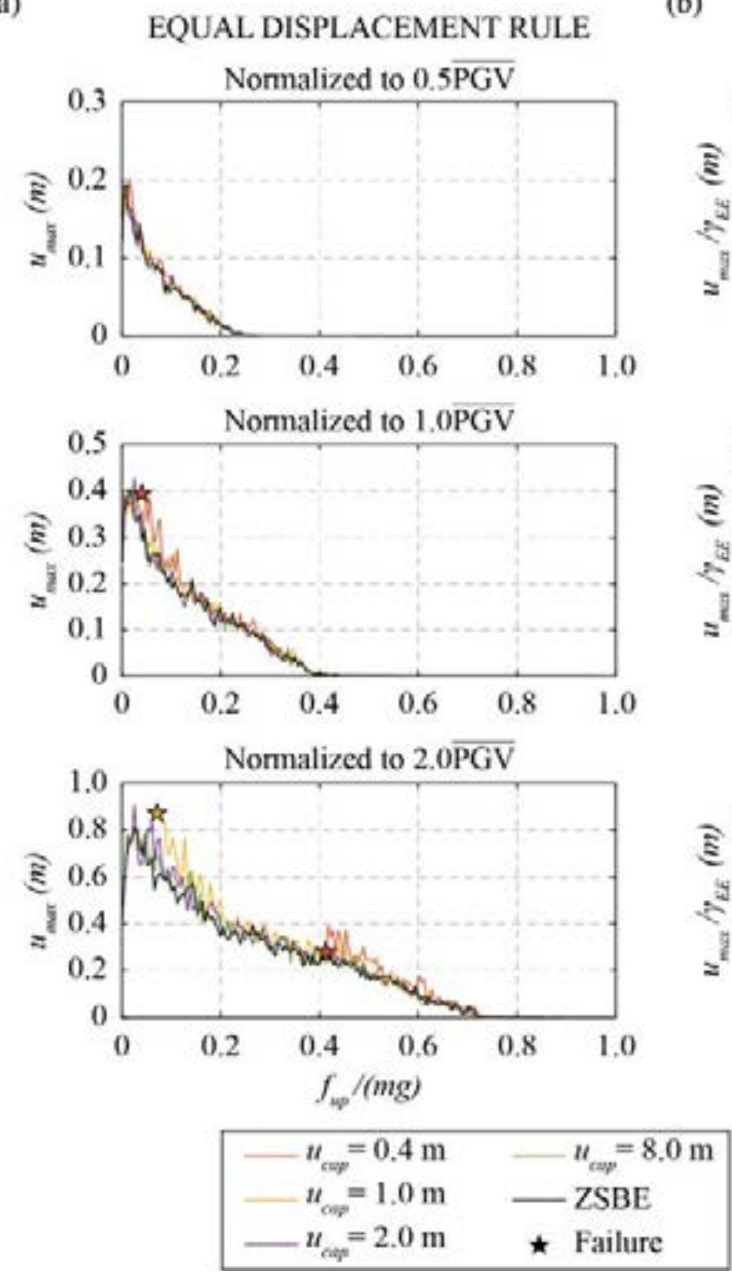

(b)
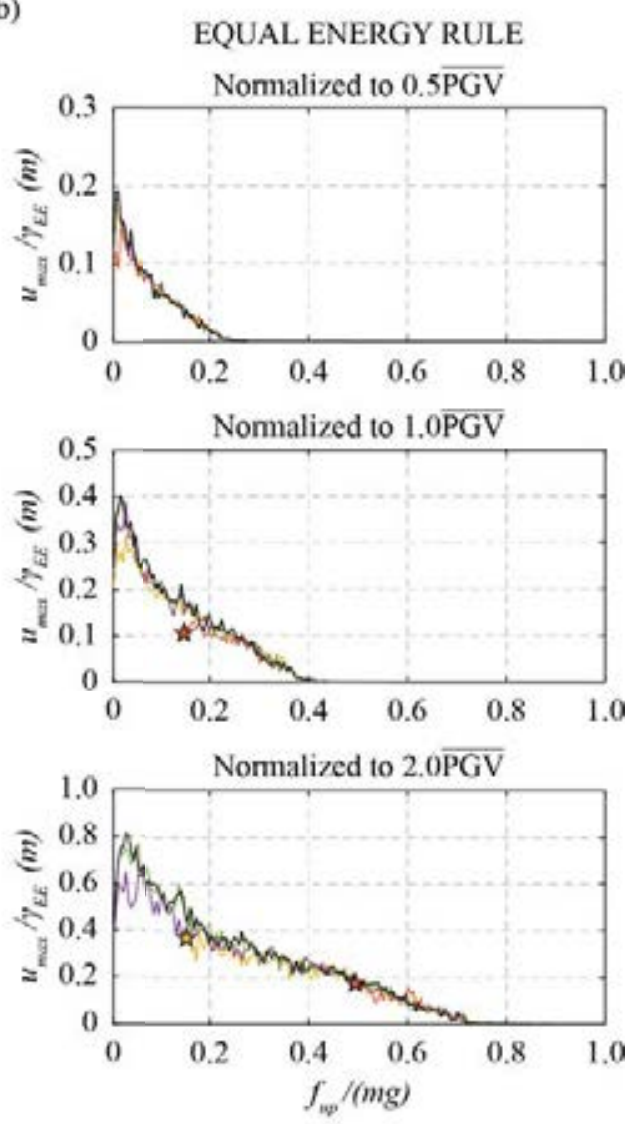

$$
\begin{aligned}
& \overline{\mathrm{PGD}}=16.55 \mathrm{~cm} \\
& \overline{\mathrm{PGV}}=40.09 \mathrm{~cm} / \mathrm{s} \\
& \overline{\mathrm{PGA}}=0.37 \mathrm{~g}
\end{aligned}
$$

Figure 3: a) Median displacement spectra; b) Median displacement spectra normalized by $\gamma_{E E}$

The above conclusions also hold for the near-field pulse-like and near-field no pulse-like FEMA ground motion sets [47].

\subsection{Design Example}

Next, a case study is used to illustrate a design method based on the Equal Displacement and Equal Energy rules. The method is applied for the design of a rocking bridge equipped with a restraining system that increases the displacement capacity, while keeping the postuplift stiffness negative.

The geometry of the bridge is typical of overpass bridges. The columns have a height of $9.6 \mathrm{~m}$ and a diameter of $1.6 \mathrm{~m}$, whereas the deck is much heavier than the columns $\left(\gamma_{m} \rightarrow \infty\right)$. Planar rocking (i.e., one directional excitation) is assumed as a first approximation (even though this has been proven unconservative $[3,20])$. Then, the proposed design steps are: 
1. Calculate the normalized yielding strength of the system $\left(f_{u p} /(m g)\right)$. If the restraining tendon is not prestressed, this depends solely on the column geometry, and is equal to $\alpha$.

2. Obtain the displacement demand for the infinite capacity curve $\left(u_{\text {dem }, Z S}\right)$ using the ZSBE curves. The ZSBE curves are the median response of the system subjected to ensembles of ground motions.

3. Calculate the design displacement capacity of the system, as:

$$
u_{\text {cap }}=F S \cdot u_{d e m, N S}=F S \cdot \gamma \cdot u_{d e m, Z S}
$$

in which FS is a safety factor and $\gamma$ is defined by Eq. 9. Two alternative approaches were evaluated: One based on the Equal Displacement $(\gamma=1)$ and one on the Equal Energy $(\gamma=$ $\gamma_{E E}$, Eq.7) rule.

Table 2 presents the design values when the two rules are applied on the set of ground motions under the three different scalings. $u_{\text {cap }}$ is the capacity required for a $F S=2.5$ (Eq.9). For a system with a displacement capacity $u_{c a p}, u_{d e m, T H}$ is the median displacement demand of each set computed with time history analysis. $u_{d e m, E D}$ and $u_{d e m, E E}$ are equal to $\gamma_{E D} \cdot u_{d e m}, Z S$ and $\gamma_{E E} \cdot U_{d e m}, Z S$, respectively. $u_{d e m}, Z S$ is the median response of the ZSBE system. The error is defined as error $=\left(u_{d e m, E D / E E}-u_{d e m, T H}\right) / u_{d e m, T H}$.

\begin{tabular}{c|ccc|ccc}
\hline & \multicolumn{3}{|c|}{ Equal Displacement } & \multicolumn{3}{c}{ Equal Energy } \\
\hline & $\mathbf{0 . 5} \overline{\mathbf{P G V}}$ & $\mathbf{1 . 0} \overline{\mathbf{P G V}}$ & $\mathbf{2 . 0} \overline{\mathbf{P G V}}$ & $\mathbf{0 . 5} \overline{\mathbf{P G V}}$ & $\mathbf{1 . 0} \overline{\mathbf{P G V}}$ & $\mathbf{2 . 0} \overline{\mathbf{P G V}}$ \\
\hline $\boldsymbol{u}_{\text {cap }} \mathbf{( m )}$ & 1.60 & 1.60 & 1.60 & 1.60 & 1.60 & 1.60 \\
$\boldsymbol{u}_{\text {dem, } \boldsymbol{T H}}(\mathbf{m})$ & 0.031 & 0.169 & 0.447 & 0.031 & 0.169 & 0.447 \\
$\boldsymbol{u}_{\text {dem, } \boldsymbol{E D} \boldsymbol{D}(\mathbf{m})}$ & 0.030 & 0.152 & 0.449 & 0.030 & 0.159 & 0.540 \\
Error (\%) & -2.65 & -10.56 & 0.41 & -8.61 & -5.87 & 20.78 \\
\hline
\end{tabular}

Table 2: Design Values for the Equal Displacement $(\gamma=1)$ and Equal Energy rule $\left(\gamma=\gamma_{E E}\right)$

The Equal Displacement rule, in general, underpredicts the result, with a maximum underprediction error of $10 \%$. The Equal Energy rule is conservative in 1 out of 3 cases. None of the rules led to collapse, because of the safety factor FS $=2.5$.

\section{CONCLUSIONS}

Rocking systems (free, restrained, or with curved extensions) that exhibit negative postuplift stiffness can be described as elastic bilinear oscillators with a negative stiffness second branch, herein denoted as NSBE. This description can also take into account their pre-uplift deformability.

In this paper, it was proposed that these systems can be described by an equivalent bilinear elastic system that has the same strength, zero post-uplift stiffness, and zero uplift displacement, i.e. a one-parameter system, a ZSBE system with zero uplift displacement. Based on this equivalent system, the response of the original negative stiffness oscillator can be obtained by either an "Equal Displacement rule" or an "Equal Energy rule", the former being simpler, the latter being more accurate. The above methodology is similar to the " $R \mu T$ " concept for elastoplastic structures with one fundamental difference: The equivalent system is not linear elastic, but a bilinear elastic system with zero stiffness of the second branch (ZSBE). 
This equivalence suggests that the ZSBE oscillator should be extensively studied under a larger database of recorded ground motions to derive non-linear spectra describing its behavior. This will provide the engineering community with a tool to easily design rocking (or any other negative stiffness bilinear elastic) structures, without having to perform time consuming time history analysis.

\section{ACKNOWLEDGEMENT}

This work was supported by the ETH Zurich under grant ETH-10 18-1.

\section{REFERENCES}

[1] N. Makris, M.F. Vassiliou, Planar rocking response and stability analysis of an array of free-standing columns capped with a freely supported rigid beam. Earthq. Eng. Struct. Dyn., 42, 431-449, 2012.

[2] P. Sideris, A. J. Aref, and A. Filiatrault, Quasi-Static Cyclic Testing of a Large-Scale Hybrid Sliding-Rocking Segmental Column with Slip-Dominant Joints. J. Bridg. Eng., 19 (10), 04014036, 2014.

[3] M. F. Vassiliou, Seismic response of a wobbling 3D frame. Earthq. Eng. Struct. Dyn., 47 (5), 1212-1228, 2018.

[4] J. A. Bachmann, M. Strand, M. F. Vassiliou, M. Broccardo, and B. Stojadinović, Is rocking motion predictable?. Earthq. Eng. Struct. Dyn., 47 (2), 535-552, 2018.

[5] A. Dar, D. Konstantinidis, and W. El-Dakhakhni, Seismic response of rocking frames with top support eccentricity. Earthq. Eng. Struct. Dyn., 47 (12), 2496-2518, 2018.

[6] M. M. Kashani, A. Gonzalez-Buelga, R. P. Thayalan, A. R. Thomas, and N. A. Alexander, Experimental investigation of a novel class of self-centring spinal rocking column. J. Sound Vib., 437, 308-324, 2018.

[7] Y. Xie, J. Zhang, R. DesRoches, and J. E. Padgett, Seismic fragilities of single-column highway bridges with rocking column-footing. Earthq. Eng. Struct. Dyn., 48 (7), 843864, 2019.

[8] J. A. Bachmann, M. F. Vassiliou, and B. Stojadinovic, Rolling and rocking of rigid uplifting structures. Earthq. Eng. Struct. Dyn., 48 (14), 1556-1574, 2019.

[9] R. Thiers-Moggia and C. Málaga-Chuquitaype, Seismic protection of rocking structures with inerters. Earthq. Eng. Struct. Dyn., 48 (5), 528-547, 2019.

[10] A. I. Giouvanidis and Y. Dong, Seismic loss and resilience assessment of singlecolumn rocking bridges. Bull. Earthq. Eng., 18 (9), 4481-4513, 2020.

[11] M. Sieber, S. Klar, M. F. Vassiliou, and I. Anastasopoulos, Robustness of simplified analysis methods for rocking structures on compliant soil. Earthq. Eng. Struct. Dyn., 49 (14), 1388-1405, 2020.

[12] I. M. Thomaidis, A. J. Kappos, and A. Camara, Dynamics and seismic performance of rocking bridges accounting for the abutment-backfill contribution. Earthq. Eng. Struct. Dyn., 49 (12), 1161-1179, 2020.

[13] N. Makris and M. F. Vassiliou, Are Some Top-Heavy Structures More Stable?. J. 
Struct. Eng., 140 (5), 06014001, 2014.

[14] N. Makris and M. F. Vassiliou, Dynamics of the Rocking Frame with Vertical Restrainers. J. Struct. Eng., 141 (10), 04014245, 2015.

[15] E. G. Dimitrakopoulos and A. I. Giouvanidis, Seismic Response Analysis of the Planar Rocking Frame. J. Eng. Mech., 141 (7), 04015003, 2015.

[16] M. F. Vassiliou and N. Makris, Dynamics of the Vertically Restrained Rocking Column. J. Eng. Mech., 141 (12), 04015049, 2015.

[17] A. Agalianos, A. Psychari, M. F. Vassiliou, B. Stojadinovic, and I. Anastasopoulos, Comparative assessment of two rocking isolation techniques for a motorway overpass bridge. Front. Built Environ., 3, 1-19, 2017.

[18] A. I. Giouvanidis and E. G. Dimitrakopoulos, Seismic Performance of Rocking Frames with Flag-Shaped Hysteretic Behavior. J. Eng. Mech., 143 (5), 04017008, 2017.

[19] M. F. Vassiliou, K. R. Mackie, and B. Stojadinovic, A finite element model for seismic response analysis of deformable rocking frames. Earthq. Eng. Struct. Dyn., 46 (3), 447-466, 2016.

[20] M. F. Vassiliou, S. Burger, M. Egger, J. A. Bachmann, M. Broccardo, and B. Stojadinovic, The three-dimensional behavior of inverted pendulum cylindrical structures during earthquakes. Earthq. Eng. Struct. Dyn., 46 (14), 2261-2280, 2017.

[21] J. A. Bachmann, M. F. Vassiliou, and B. Stojadinovic, Dynamics of rocking podium structures. Earthq. Eng. Struct. Dyn., 46 (14), 2499-2517, 2017.

[22] M. Aghagholizadeh and N. Makris, Earthquake response analysis of yielding structures coupled with vertically restrained rocking walls. Earthq. Eng. Struct. Dyn., 47 (15), 2965-2984, 2018.

[23] G. Ríos-García and A. Benavent-Climent, New rocking column with control of negative stiffness displacement range and its application to RC frames. Eng. Struct., 206, 110133, 2020.

[24] G. W. Housner, The behavior of inverted pendulum structures during earthquakes. Bull. Seismol. Soc. Am., 53 (2), 403-417, 1963.

[25] A. Dar, D. Konstantinidis, and W. W. El-Dakhakhni, Evaluation of ASCE 43-05 Seismic Design Criteria for Rocking Objects in Nuclear Facilities. J. Struct. Eng., 142 (11), 04016110, 2016.

[26] D. Kalliontzis, S. Sritharan, and A. Schultz, Improved Coefficient of Restitution Estimation for Free Rocking Members. J. Struct. Eng., 142 (12), $06016002,2016$.

[27] M. N. Chatzis, M. G. Espinosa, and A. W. Smyth, Examining the Energy Loss in the Inverted Pendulum Model for Rocking Bodies. J. Eng. Mech., 143 (5), $04017013,2017$.

[28] A. G. Sextos, G. D. Manolis, N. Ioannidis, and A. Athanasiou, Seismically induced uplift effects on nuclear power plants. Part 2: Demand on internal equipment. Nucl. Eng. Des., 318, 288-296, 2017.

[29] A. I. Giouvanidis and E. G. Dimitrakopoulos, Nonsmooth dynamic analysis of sticking impacts in rocking structures. Bull. Earthq. Eng., 15 (5), 2273-2304, 2017.

[30] E. Voyagaki, P. Kloukinas, M. Dietz, L. Dihoru, T. Horseman, O. Oddbjornsson, A.J. 
Crewe, C. A. Taylor, A. Steer, Earthquake response of a multiblock nuclear reactor graphite core: Experimental model vs simulations. Earthq. Eng. Struct. Dyn., 47 (13), 2601-2626, 2018.

[31] L. Di Sarno, G. Magliulo, D. D’Angela, and E. Cosenza, Experimental assessment of the seismic performance of hospital cabinets using shake table testing. Earthq. Eng. Struct. Dyn., 48 (1), 103-123, 2019.

[32] Y. Bao and D. Konstantinidis, Dynamics of a sliding-rocking block considering impact with an adjacent wall. Earthq. Eng. Struct. Dyn., 49 (5), 498-523, 2020.

[33] C. Christopoulos, A. Filiatrault, and B. Folz, Seismic response of self-centring hysteretic SDOF systems. Earthq. Eng. Struct. Dyn., 31 (5), 1131-1150, 2002.

[34] A. Palermo, S. Pampanin, and G. M. Calvi, Concept and development of hybrid solutions for seismic resistant bridge systems. J. Earthq. Eng., 9 (6), 899-921, 2005.

[35] N. Makris and D. Konstantinidis, The rocking spectrum and the limitations of practical design methodologies. Earthq. Eng. Struct. Dyn., 32 (2), 265-289, 2003.

[36] S. Polyakov, Design of Earthquake Resistant Structures. Mir. Publishers., 1974.

[37] A. K. Chopra and S. C. -S. Yim, Simplified Earthquake Analysis of Structures with Foundation Uplift. J. Struct. Eng., 111 (4), 906-930, 1985.

[38] I. N. Psycharis, Effect of base uplift on dynamic response of SDOF structures. J. Struct. Eng., 117 (3), 733-754, 1991.

[39] I. Anastasopoulos, R. Kourkoulis, F. Gelagoti, and E. Papadopoulos, Rocking response of SDOF systems on shallow improved sand: An experimental study. Soil Dyn. Earthq. Eng., 40, 15-33, 2012.

[40] S. Acikgoz and M. J. DeJong, The interaction of elasticity and rocking in flexible structures allowed to uplift. Earthq. Eng. Struct. Dyn., 41 (15), 2177-2194, 2012.

[41] M. F. Vassiliou, K. R. Mackie, and B. Stojadinovic, Dynamic response analysis of solitary flexible rocking bodies: modeling and behavior under pulse-like ground excitation. Earthq. Eng. Struct. Dyn., 43 (10), 1462-1481, 2014.

[42] M. F. Vassiliou, R. Truniger, and B. Stojadinovic, An analytical model of a deformable cantilever structure rocking on a rigid surface: development and verification. Earthq. Eng. Struct. Dyn., 44 (15), 2775-2794, 2015.

[43] R. Truniger, M. F. Vassiliou, and B. Stojadinovic, An analytical model of a deformable cantilever structure rocking on a rigid surface: experimental validation. Earthq. Eng. Struct. Dyn., 44 (15), 2795-2815, 2015.

[44] E. Avgenakis and I. N. Psycharis, Modeling of Inelastic Rocking Bodies under Cyclic Loading. J. Eng. Mech., 146 (4), 04020020, 2020.

[45] FEMA P695, Quantification of Building Seismic Performance Factors, Federal Emergency Manangement Agency, Rep. FEMA P695, Washington, DC, 2009.

[46] M. F. Vassiliou, M. Broccardo, C. Cengiz, M. Dietz, L. Dihoru, S. Gunay, K. M. Mosalam,G. Mylonakis, A. Sextos, B. Stojadinovic, Shake table testing of a rocking podium: Results of a blind prediction contest. Earthq. Eng. Struct. Dyn., 50 (4), $1043-$ 1062, 2021.

[47] N. Reggiani Manzo and M. F. Vassiliou, Simplified analysis of bilinear elastic systems 
exhibiting negative stiffness behavior. Earthq. Eng. Struct. Dyn., 50 (2), 580-600, 2021. 